\title{
Sourcing from China: A Literature Review of Motivations, Outcomes, Problems, and Solutions
}

\author{
Kristina Kerkhoff \\ Department of Industrial Engineering and Management, School of Engineering, \\ Jönköping University, P.O. Box 1026, SE-551 11, Jönköping, Sweden \\ Email: Kristina.Kerkhoff@gmail.com (Corresponding Author) \\ Kevin Kaul \\ Department of Industrial Engineering and Management, School of Engineering, \\ Jönköping University, P.O. Box 1026, SE-551 11, Jönköping, Sweden \\ Email: Kevin.Kaul2@gmail.com
}

\author{
Per Hilletofth \\ Department of Industrial Engineering and Management, School of Engineering, \\ Jönköping University, P.O. Box 1026, SE-551 11, Jönköping, Sweden \\ Email: prof.p.hilletofth@gmail.com \\ David Eriksson \\ Department of Industrial Engineering and Management, School of Engineering, \\ Jönköping University, P.O. Box 1026, SE-551 11, Jönköping, Sweden \\ Email: dr.d.eriksson@gmail.com
}

\begin{abstract}
Today's fast changing environment and increasing customers' demands require that companies focus on efficiency along the entire supply chain. In order to achieve competitiveness, global sourcing is a common strategy. Especially sourcing from China is an accustomed practice and the topic of discussion by various academics and practitioners. Even though this topic is discussed extensively in literature, little focus is put on motivations, outcomes, problems and solutions when sourcing from China. The purpose of this study is to explore and analyze sourcing from China sourcing with regard to motivations, achieved outcomes, experienced problems as well as solutions to the problems. The results showed that it is crucial to recognize the importance of problems that can occur during global sourcing processes. As to achieve the desired outcomes, it is vital that companies address the problems by developing appropriate solutions. Motivations, outcomes, problems and solutions contain essential aspects that have to be considered and worked upon during a global sourcing process.
\end{abstract}

Keywords: global sourcing, China, motivations, outcomes, problems, solutions

\section{INTRODUCTION}

Offshoring and outsourcing represent two fairly common sourcing strategies (Coyle et al., 2013; Hilletofth and Hilmola, 2010; Solli-Saether \& Gottschalk, 2015). Accompanying benefits and risks of various sourcing strategies are the subject of discussion by a variety of academics and practitioners (e.g. Holweg et al., 2011;
Åkesson et al., 2007; Wiesmann et al., 2017). Benefits of sourcing from developing countries, like China, cover aspects such as cost savings, increased capacity, enhanced flexibility and access to skilled and qualified human resources (Coyle et al., 2013; Harland et al., 2005). Despite the potential rewards, geographical distances and legal or cultural differences threaten the success of offshored and outsourced businesses (Kremic et al., 2006; Salanta et al., 2011; Dicken, 2011; Dibbern, Winkler \& Heinzl, 2008). For companies, it is important to understand potential tradeoffs, which is highlighted by the numerous examples of offshoring gone wrong (e.g. Canham \& Hamilton, 2013; Kinkel \& Maloca, 2009). Here, academics can assist by summarizing current knowledge, which is also something important for an ongoing research process devoted to contributions, substantiations and theory building (Svensson, 2013).

Even though literature on sourcing from China is available, it is important to summarize the research in a structured manner, so as to understand the motivations, outcomes, encountered problems and problem-solving approaches. In contrast to high expectations and motivations for global sourcing, Dibbern et al. (2008) highlight that up to 50 per cent of offshore projects fail to reach expected cost savings. The given example underlines that the motivations for global sourcing approaches seem to be more elaborated and precise, while the actual performance is not researched in depth (Wang et al., 2011; Najafi, Dubois \& Hulthen, 2013; Gray \& Meister, 2004). Furthermore, there is a lack in research as the environment in China is changing rapidly (Purdy et al., 2014). As the global dynamics change, motivations, outcomes, problems, and solutions when 
sourcing from China are probably not the same as they were ten years ago (Wang et al., 2011). As such, it is important to create an overview of the current knowledge, so as to construct a base of knowledge which can be expanded on in the future (Eriksson, 2015).

The purpose of this study is to explore and analyze sourcing from China. The specific research questions are:

1. 'What are the motivations for sourcing from China?',

2. 'What outcomes are achieved while sourcing from China?',

3. 'What problems are encountered while sourcing from China?',

4. 'How are these problems dealt with?'.

The questions above have been examined through a systematic literature review. As to answer these research questions, a predefined spreadsheet containing the different steps was developed to support and guide the systematic character of the data collection process. Afterwards, descriptive and content analyses were performed.

The remainder of this paper is structured as follows: In Section two, the research methodology of the study is discussed in more depth. Afterwards, a descriptive analysis is carried out in Section three. Subsequently, the findings of the study are presented and discussed in Sections four and five. Finally, in Section six the conclusion of this study is presented.

\section{RESEARCH METHOD}

\subsection{Research Strategy}

The systematic literature review used in this research aims at presenting the current state of knowledge on sourcing from China. As extensive theory exists on the topic global sourcing, including offshoring and outsourcing, this systematic literature review adds value due to its particular focus on motivations, outcomes, problems and solutions when sourcing from China. The methodological approach, illustrated in Figure 1, follows the logic as discussed by Gimenez and Tachizawa (2012). In line with the systematic character of the research, a high level of transparency was created and researcher bias was reduced (Adolphos, 2015; Carter \& Easton, 2011; Aromataris \& Pearson, 2014).

\subsection{Data Collection}

Initially, various search terms were identified, referring back to the four research areas, which is illustrated in Table 1. Thereafter, the database was selected (SCOPUS) in a second step.
The delimitations for the data collection process were defined in the third step. Articles were selected from online, peer-reviewed journals, written in English, published between 1996 and February 2015 in the field of 'Social Sciences and Humanities'. The search terms were defined to be part of the article title, the abstract, or the keywords. This process is shown in Table 2.

The search processes were defined in a fourth step. These were carried out with the help of the Boolean logic, which is frequently employed for search combinations. This logic is defined as a "system by which the variety of items found in a search [is] based on logical propositions that can be either true or false can be combined, limited or widened" (Saunders et al., 2012, p. 666). Overall, four complex search strings were identified aiming at answering the research questions as highlighted in Table 3. Both, the field of sourcing and the term 'China' were part of all of them. The field of sourcing was part of the search string by utilizing the terms 'sourcing' or 'outsourcing' or 'offshoring' at the same time. In addition to the mentioned search terms 'sourcing' or 'outsourcing' or 'offshoring' and 'China', one area of either 'motivations', or 'outcomes', or 'problems', or 'solutions' was added. All of these areas were identified with the help of synonymous words.

The previously described search process consisting of four different search strings resulted in a total of 214 potentially relevant articles as illustrated in Table 4 below. Thereafter, abstract reviews were carried out and articles that were irrelevant or appeared twice were excluded. Therefore, some articles contained relevant information for more than one category. 81 relevant articles were identified and an entire paper review was undertaken with all of them. The number of remaining articles that were relevant resulted in 49. All 49 articles were reviewed and relevant aspects and explanations were collected in a database.

\subsection{Data Analysis}

As reported by Brewerton and Millward (2001), a systematic literature review is composed of both a descriptive and a content analysis, whereby quantitative and qualitative aspects are mixed. The descriptive analysis consists of formal criteria such as the year of publication, the journal of publication, the industry and the region of publication (Mayring, 2003). In a second step, the content analysis was carried out according to the four categories of motivations, outcomes, problems and solutions. Within each of the four categories all results were quantified. The data was then listed in a ranked manner, starting with the highest frequency.

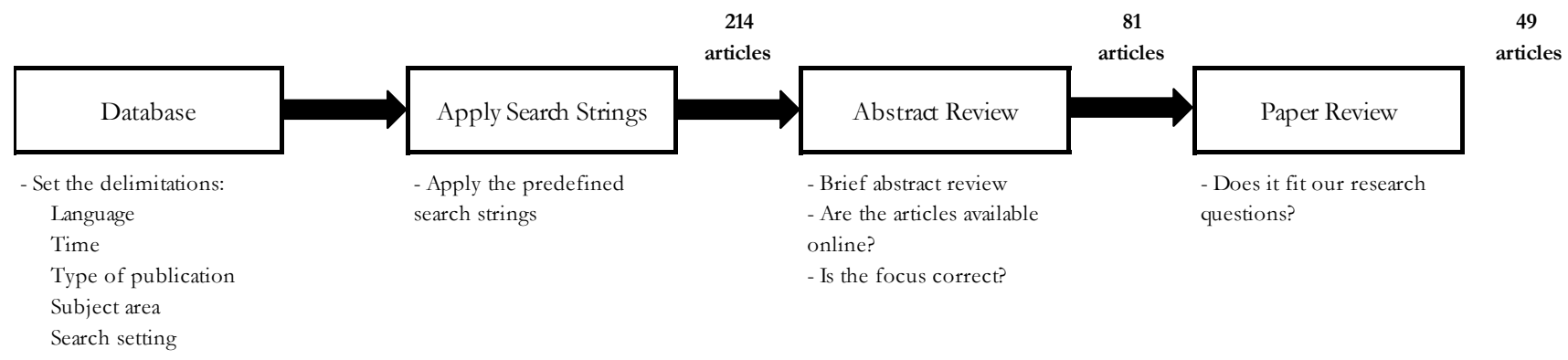

Figure 1 Screening approach (Adapted from Gimenez and Tachizawa 2012) 
Table 1 Search terms (Title, abstract, keywords)

\begin{tabular}{|c|c|}
\hline Term & Search terms \\
\hline \multirow{3}{*}{ Sourcing } & Sourcing \\
\hline & Offshoring \\
\hline & Outsourcing \\
\hline China & China \\
\hline \multirow{4}{*}{ Motivations } & Drivers \\
\hline & Reasons \\
\hline & Motives \\
\hline & Motivations \\
\hline \multirow{4}{*}{ Outcomes } & Results \\
\hline & Achievements \\
\hline & Outcomes \\
\hline & Performance \\
\hline \multirow{4}{*}{ Difficulties } & Obstacles \\
\hline & Barriers \\
\hline & Drawbacks \\
\hline & Difficulties \\
\hline \multirow{4}{*}{ Problem Solving } & Solution \\
\hline & Deal with Problem \\
\hline & Problem resolution \\
\hline & Problem solving \\
\hline
\end{tabular}

Table 2 Delimitations

\begin{tabular}{|l|l|}
\hline Delimitation & Explanation \\
\hline Language & 1996 - present \\
\hline Time & Journal \\
\hline Type of publication & Social Sciences \& Humanities only \\
\hline Subject area & Article Title, Abstract, Keywords \\
\hline Search setting &
\end{tabular}

Table 3 Combinations of search terms (Boolean logic)

\begin{tabular}{|l|l|}
\hline Combination & \begin{tabular}{l} 
Search terms \\
\hline 1
\end{tabular} \\
\hline 2 & $\begin{array}{l}\text { "Sourcing" OR "Outsourcing" OR "Offshoring" AND "China" AND "Motivations" OR "Drivers" } \\
\text { OR "Reasons" OR "Motives" } \\
\text { "Achievements" OR "Performance" }\end{array}$ \\
\hline 3 & $\begin{array}{l}\text { "Sourcing" OR "Outsourcing" OR "Offshoring" AND "China" AND "Difficulties" OR "Obstacles" } \\
\text { OR "Barriers" OR "Drawbacks" }\end{array}$ \\
\hline 4 & $\begin{array}{l}\text { "Sourcing" OR "Outsourcing" OR "Offshoring" AND "China" AND "Problem Solving" OR } \\
\text { "Solution" OR "Deal with Problem" OR "Problem resolution" }\end{array}$ \\
\hline
\end{tabular}


Table 4 Sample size after abstract and paper review

\begin{tabular}{|c|c|c|c|c|}
\hline Combinations & $\begin{array}{l}\text { No. of papers } \\
\text { after } 1 \text { st } \\
\text { exclusion }\end{array}$ & $\begin{array}{l}\text { 1. Exclusion } \\
\text { criteria }\end{array}$ & $\begin{array}{l}\text { No. of papers } \\
\text { after } 2 \text { nd } \\
\text { exclusion }\end{array}$ & $\begin{array}{l}\text { 2. Exclusion } \\
\text { criteria }\end{array}$ \\
\hline $\begin{array}{l}\text { "Sourcing" OR "Outsourcing" OR } \\
\text { "Offshoring" AND "China" AND } \\
\text { "Motivations" OR "Drivers" OR } \\
\text { "Reasons" OR "Motives" }\end{array}$ & 17 & $\begin{array}{l}\text { Wrong focus, } \\
\text { recurring articles, } \\
\text { few articles not } \\
\text { available }\end{array}$ & 13 & $\begin{array}{l}\text { Wrong focus, } \\
\text { industry not } \\
\text { applicable }\end{array}$ \\
\hline $\begin{array}{l}\text { "Sourcing" OR "Outsourcing" OR } \\
\text { "Offshoring" AND "China" AND } \\
\text { "Results" OR "Outcomes" OR } \\
\text { "Achievements" OR "Performance" }\end{array}$ & 52 & $\begin{array}{l}\text { Wrong focus, } \\
\text { recurring articles, } \\
\text { few articles not } \\
\text { available }\end{array}$ & 27 & $\begin{array}{l}\text { Wrong focus, } \\
\text { industry not } \\
\text { applicable }\end{array}$ \\
\hline $\begin{array}{l}\text { "Sourcing" OR "Outsourcing" OR } \\
\text { "Offshoring" AND "China" AND } \\
\text { "Difficulties" OR "Obstacles" OR } \\
\text { "Barriers" OR "Drawbacks" }\end{array}$ & 6 & $\begin{array}{l}\text { Wrong focus, } \\
\text { recurring articles, } \\
\text { few articles not } \\
\text { available }\end{array}$ & 4 & $\begin{array}{l}\text { Wrong focus, } \\
\text { industry not } \\
\text { applicable }\end{array}$ \\
\hline $\begin{array}{l}\text { "Sourcing" OR "Outsourcing" OR } \\
\text { "Offshoring" AND "China" AND } \\
\text { "Problem Solving" OR "Solution" OR } \\
\text { "Deal with Problem" OR "Problem } \\
\text { resolution" }\end{array}$ & 6 & $\begin{array}{l}\text { Wrong focus, } \\
\text { recurring articles, } \\
\text { few articles not } \\
\text { available }\end{array}$ & 5 & $\begin{array}{l}\text { Wrong focus, } \\
\text { industry not } \\
\text { applicable }\end{array}$ \\
\hline Sample & 81 & & 49 & \\
\hline
\end{tabular}

\section{DESCRIPTIVE ANALYSIS}

\subsection{Distribution across the Time Period and Main Journals}

As illustrated in Figure 2, the final sample of 49 articles is distributed between the years 1997 and 2014. For most of the years, one to five articles were found in the sample, with a few exceptions. There is only one article published in 1997, and the next one in 2003. In 2010, 11 articles relevant for the topic were identified. This distribution can partly be explained because global sourcing has been widely adopted since the beginning of 2000 (Christopher et al., 2011; Susomrith \& Brown, 2013) and China joined the World Trade Organization in 2001 (World Trade Organization, 2015). No relevant articles for 2015 were identified, but this is more likely a result of the time when the investigation was performed.

'Supply Chain Management: An International Journal' was the outlet with the most publications. 'International Journal of Production Economics', 'Journal of Business Ethics', and 'Journal of Purchasing \& Supply Management' respectively had three publications. These four journals published a total of 25 out of the 49 included articles. Each of the remaining 24 articles was published in separate journals.

The author affiliation of the articles was distributed across three main regions, namely Europe, North America and Asia Pacific. Sometimes, a combination of regions was the subject of discussion within one article. However, in some articles the region was not specified or kept on a global level. Discussing the sample size from a point of view of the applied industries, manufacturing industries were relevant within 28 of the 49 articles. While the industry has not been specified in seven articles, in three different articles further industries were discussed such as textile, retail, IT, aviation, pharmaceutical, automotive, service and consumer goods. In addition to the publication details, 23 articles outsourcing solely focused on sourcing strategy, seven articles concentrated on offshoring, and 19 articles utilize the term 'global sourcing'. In some cases, this term includes both outsourcing and offshoring, whereas other authors do not specify the term of global sourcing. 


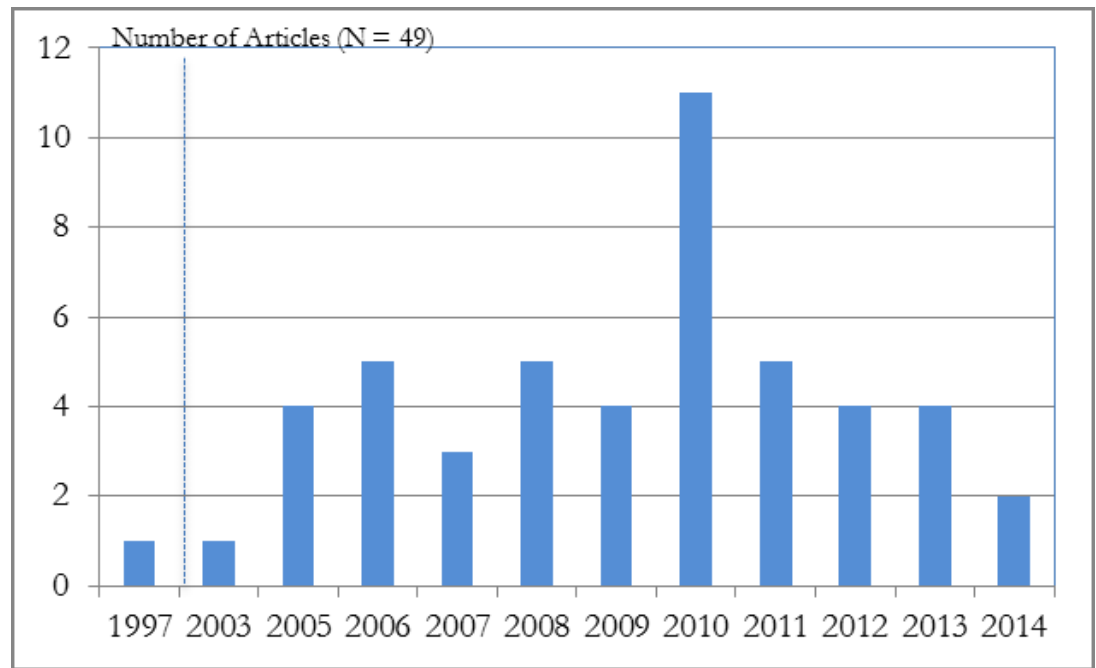

Figure 2 Distribution of articles according to year of publication

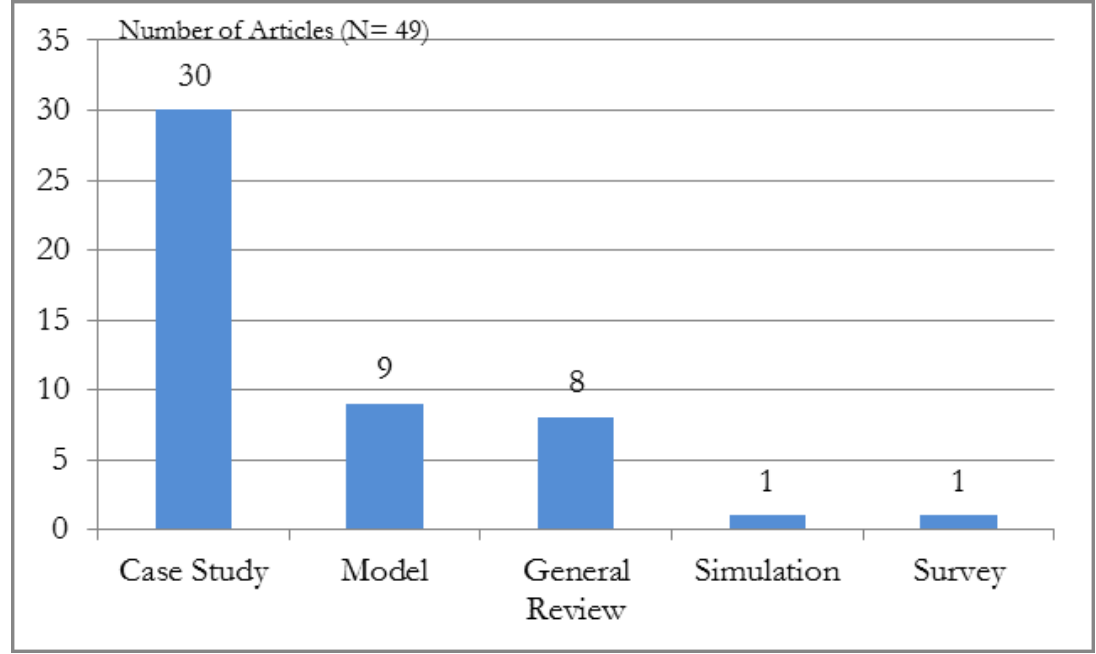

Figure 3 Distribution of utilized research methods

\subsection{Research Methodologies Applied}

The articles within the sample were grouped according to their applied method; case studies, models and general reviews were most common. As shown in Figure 3, the case study approach was utilized in 30 out of 49 articles, and is thus the most common applied research method. Even though a case study strategy is most appropriately employed in order to get insights into a rather unexplored area, it also enables the researchers to find evidence and examples from a new angle of an area (Eisenhardt, 1989), Dubois and Gadde (2002) calls this 'redirection'. Various exemplary industries and regions regarding global sourcing from China were discussed within the sample size.

\section{CONTENT ANALYSIS}

\subsection{Overview of the Key Word Types}

As discussed in the methodology, four different categories represented the search strings for the systematic literature review. These are closely connected to the research questions and focus on the four areas: motivations, outcomes, problems, and solutions, all pertaining to sourcing from China. In total, 237 relevant aspects could be gathered throughout the analysis, which is illustrated in Figure 4 below. In addition, some authors mentioned several aspects belonging to the same category and, as could be expected, various authors mentioned the same aspects. However, researchers discussed problems 82 times, and solutions only 73 times. In the following, the most frequently mentioned motivations, outcomes, problems and solutions are discussed in more depths.

\subsection{Motivations for Sourcing from China}

The most frequent motivations addressed below are summarized in Figure 5.

Considering the category of motivations, six main aspects were identified. Cost savings is the most frequently mentioned motivation for sourcing from China. Out of 49 articles, 30 mention cost savings as a motivation. These cost savings are further specified in lower production, raw material, overhead and labor costs, for instance by Kumar, Medina and Nelson (2009b), Bygballe et al. (2012), Lemoine (2010), Kamann and van Nieulande (2010), and Zhang et al. (2013). According to Jia et al. (2014, p. 290), who carried out case studies with 14 companies in Europe and North America, cost reductions represent a common motivation for all case companies, "however, in only four cases this represented the sole or main driver". Moreover, Takala et al. (2007) emphasize that in order to pursue an international 
growth strategy, it is of vital importance to benefit from low cost countries.

Besides cost savings, flexibility was the second most important motivation for sourcing from China. Flexibility is more specifically defined as "reducing the total development time" of new products (Gonzalez et al., 2006, p. 1236); achieving quick responses to changes (Li et al., 2007); and the ability "to match the unpredictability of demand" (Towers \& Song, 2010, p. 541). Moreover, high component availability of specialized or rare products is identified as a reason for sourcing from China. Especially the size of the domestic market in China emphasizes the ease to find replacements for products that cannot be sourced elsewhere (Kierzkowski, 2011; Marion et al., 2007). Thus, the growing Chinese market is attractive to enter. In this context, expansion is mentioned as a motivation, which is mainly relevant for offshoring strategies (Jia et al., 2014; Dierks et al., 2013; Kang et al., 2012; Wang et al., 2011).
Furthermore, skills and lead-time have been mentioned as motivations. Skills mainly refer to a broad skill base of Chinese suppliers regarding industries and manufacturing processes. An improvement in technology leads to knowledgeable suppliers in China, which might be even more specialized than Western countries in certain fields (Gonzalez et al., 2006; Jia et al., 2014; Stringer et al., 2011). Referring back to an offshore strategy, the lead-time to the domestic Chinese market can be decreased significantly, which presents another important motivation (Jia et al., 2014; Zhang et al., 2013).

Capacity, a focus on core competencies and a good price-quality ratio were mentioned once in one article. Large manufacturing plants in China enable firms to achieve fast production at low costs, while these firms can exclusively focus on their core competencies (Wang et al., 2011).

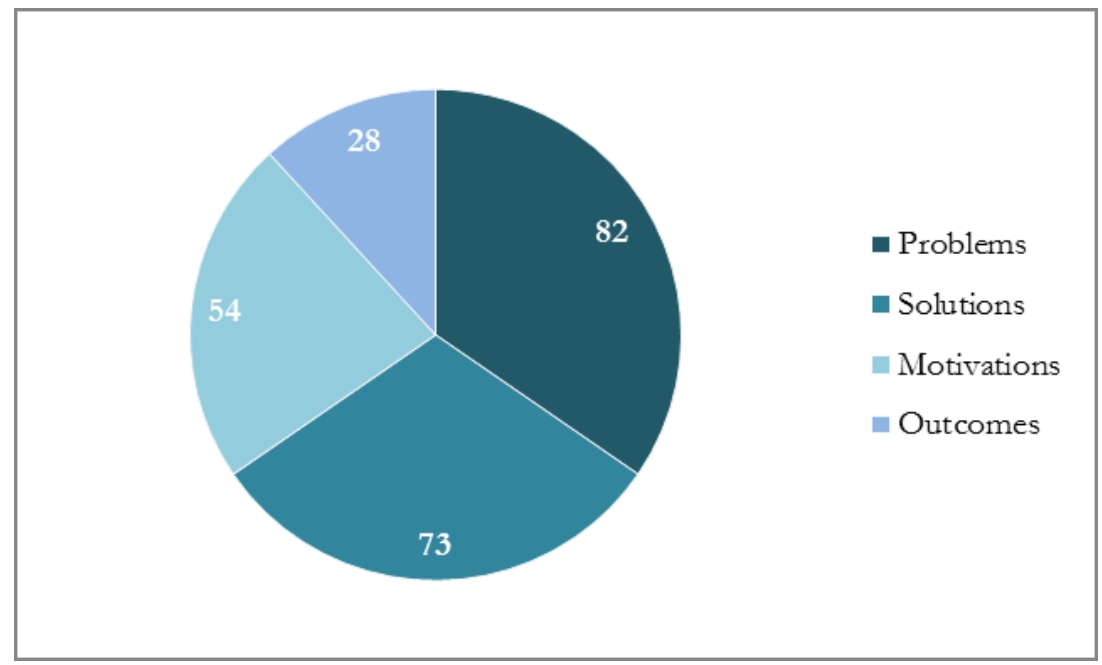

Figure 4 Frequency of key word types in the sample size

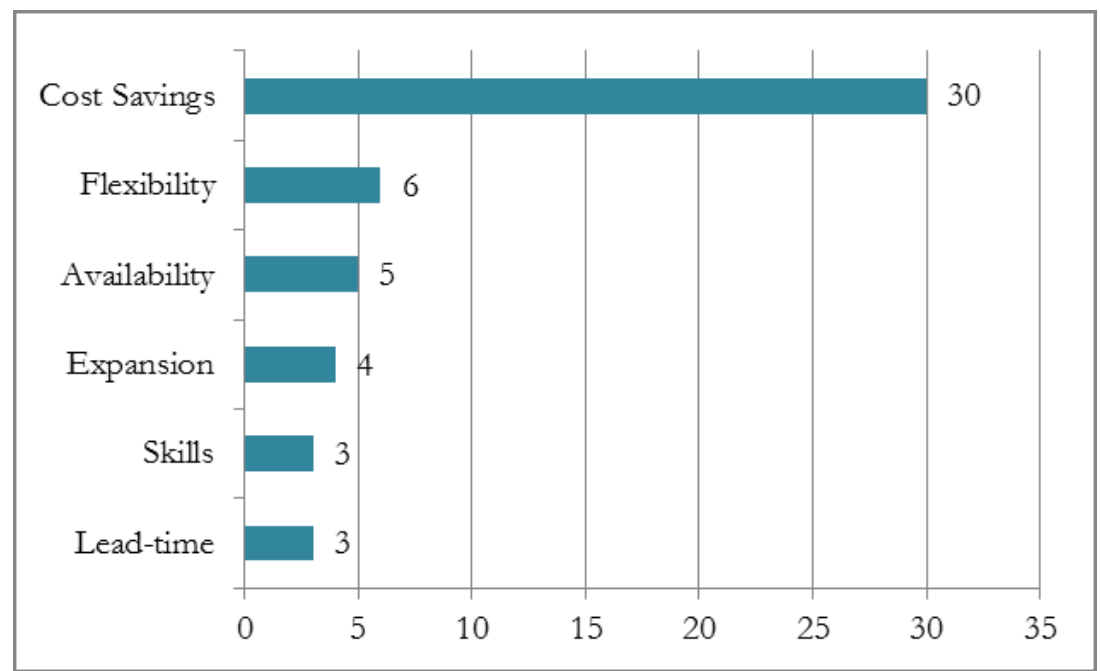

Figure 5 Most frequent motivations for sourcing from China 


\subsection{Achieved Outcomes when Sourcing from China}

The achieved outcomes addressed below are summarized in Figure 6.

The lowest amount of aspects was identified in the category of outcomes. The most common outcome is classified as a mixed one, which implies both positive and negative aspects. As stated by Wang et al. (2011, p. 426), "many of these firms did indeed achieve reductions in the cost of the inputs to their processes or products, but in many cases the anticipated cost reductions were not matched by those achieved". The quote implies that actual costs are higher than expected because of hidden or inappropriate cost calculations (see also Platts \& Song, 2010; Bygballe et al., 2012). Moreover, drivers were experienced to be overestimated in comparison to the risks (Kumar et al., 2010), and "failed low-wage-country sourcing projects would have to be replaced by other suppliers in order to ensure continuity of supply" (Horn et al., 2013, p. 33).

A gain in expertise and specific market knowledge is another outcome authors identify. In particular, knowledge can be gathered in cooperation with the suppliers that enabled the company to focus on its core competencies (Zhang et al., 2013; Salmi, 2006; Bunyaratavej et al., 2008), and access to a new market could also be developed (Drayse, 2008; Dierks et al., 2013). Only a few authors state that profitability can be enhanced, even though it represents a major motivation when sourcing from China (Kang et al., 2012; Lin \& Ma, 2012; Ni et al., 2009). Moreover, results show that competitive advantage can be generated (Li et al., 2008; Marion et al., 2007), and thereby entering new markets is facilitated (Gonzalez et al., 2006; Jia et al., 2014).

Other outcomes that were mentioned once were negative, such as bad publicity and poor performance (Ni et al., 2009; Fredriksson \& Jonsson, 2009). Companies have a lack in tracking costs and focusing on financial reports. Hence, little information exits on how beneficial cost advantages are (Salmi, 2006).

\subsection{Problems Encountered when Sourcing from China}

The encountered problems addressed below are summarized in Figure 7.

Cultural differences is the most frequently experienced problem. Besides cultural clashes on a personal level (Salmi, 2006; Enderwick, 2009), differences are risky for the success of the business relationship (Vanhonacker \& Yigang, 1997). Almost equally striking as problems resulting from cultural differences are those resulting from deficiencies in quality. According to Gonzalez et al. (2006), lacking quality is often a result of poor training, insufficient managerial knowledge, as well as communication issues. In addition, the end customer often identifies deficient quality, which leads to costly consequences requiring replacement, and compensation for damages (Sethi et al., 2011). Despite the fact that quality requirements are fixed and known by all parties involved, it is difficult to monitor quality regulations and to avoid safety risks (Dierks et al., 2013). Moreover, according to Fredriksson et al. (2010, p. 324), "product quality is still lower in China and the long weather-exposed journey between China and Europe increases the risk of scrap".

Communication has been described as part of potential quality issues, and is addressed in several articles. First, there is a language barrier between the sourcing companies and the Chinese suppliers, which is emphasized as a main challenge by Towers and Song (2010). Chen and McQueen (2010) explain that sender and receiver do not have the same understanding of encoding and decoding messages, causing misunderstandings. Second, Jia et al. (2014) highlight that an unwillingness to communicate represents another main barrier in communication: "One trait [that is lacking] was to communicate ideas clearly to subordinates and other people, including internal stakeholders, in a Western way" (Jia et al., 2014, p. 295). Especially a lack of trust and losing one's face are the reasons why Chinese suppliers do not speak freely in a business relationship. Moreover, voicing your opinion and constructive feedback are avoided in the Chinese culture, which causes problems in the relationship with Western firms (Wilkinson et al., 2005; Lin \& Ma, 2012).

Considering the Chinese laws and regulations, various articles point out that procedures are more complex than in the companies' home countries (Takala et al., 2007). Besides an increasing complexity, clarity is often lacking, causing time-consuming processes (Vanhonacker \& Yigang, 1997). According to Roloff and Aßländer (2010), sourcing from China implies the delegation of parts along the supply chain. However, if the suppliers do not honor these responsibilities, a critical loss of control occurs. Salmi (2006) identifies the geographical distance as a critical factor of losing control. An accompanying problem is the loss of intellectual property that is often connected with doing business in China (Olson $\& \mathrm{Wu}, 2011$; Wang et al., 2011). Thus, Dierks et al. (2013) emphasize that a trade-off between low costs, product safety and intellectual property has to be made.

Further problems identified were reliability, recruitment, lead-time and costs. Problems regarding the Chinese suppliers' reliability encompass the supplier fulfillment risk. Schönherr et al. (2008, p. 104) states that "supplier fulfillment risk ... estimates how accurate suppliers are in fulfilling the orders, both in terms of quality level, quantity and punctuality". Hence, a low level of reliability might lead to the necessity of holding higher inventory levels. The recruitment of suitable employees for facilities in China is a challenge. Language skills, required qualifications and employee retention are crucial aspects (Wilkinson et al., 2005; Nassimbeni \& Sartor, 2006). According to Allon and van Mieghem (2010), lead-time can be an issue due to the geographical distance to China, which implies a decline in flexibility (Woxenius, 2006). Even though costs are the main motivation for sourcing from China, "it is risky to consider exclusively the cost savings ... as many hidden or unforeseen costs may arise that reduce the quality of the service received" (Gonzalez et al., 2006, p. 1244).

\subsection{Dealing with Problems Encountered when Sourcing from China}

The identified solutions addressed below are summarized in Figure 8. 


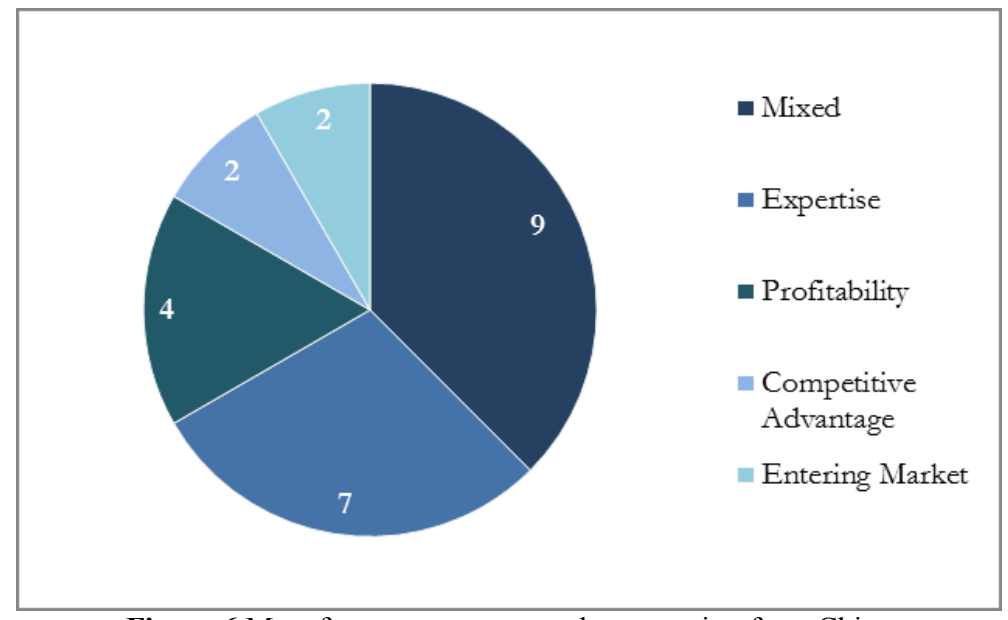

Figure 6 Most frequent outcomes when sourcing from China

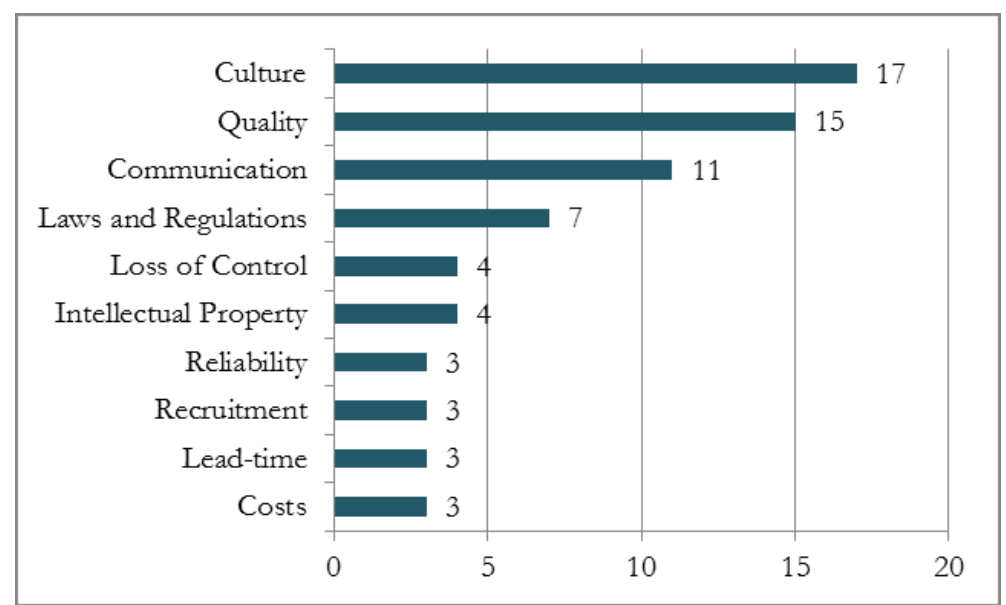

Figure 7 Most frequent problems when sourcing from China

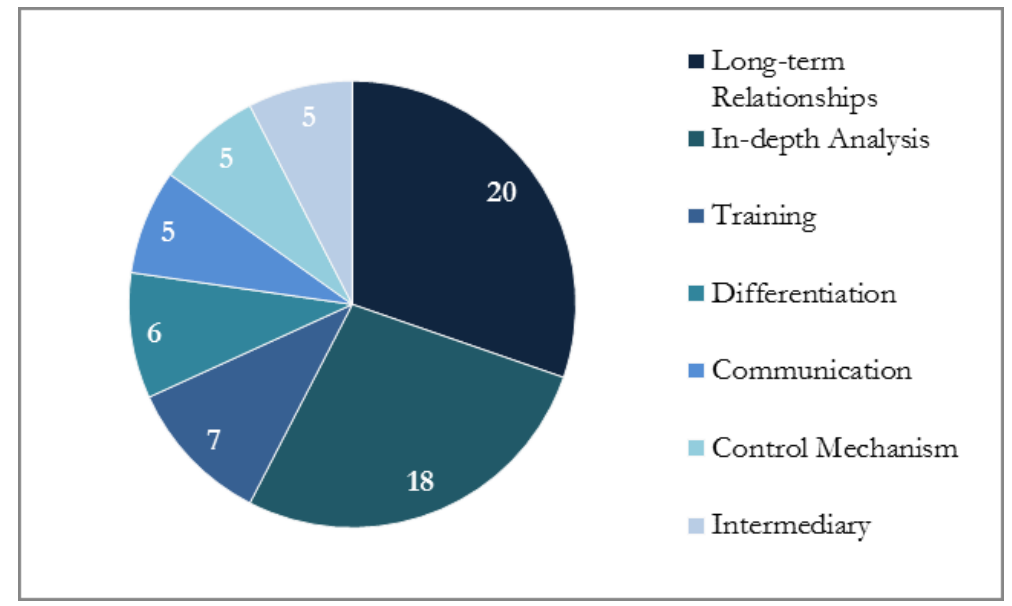

Figure 8 Most frequent problem solving approaches when sourcing from China

One of the most common solutions within the sample size is to develop a long-term relationship with the Chinese suppliers. The attention is on mutual understanding and relationships (Enderwick, 2009; Merminod \& Rowe, 2012; Chen \& McQueen, 2010; Lo \& Chung, 2007). High levels of trust can be generated by extensive collaboration between all parties involved (Zeng \& Rossetti, 2003; Gonzalez et al., 2006; Feenstra \& Hanson, 2005, and Chen et al. (2010, p. 240) point out that a good relationship encompasses teambuilding activities that help establishing "a good interpersonal relationship with providers and [enable] further interpersonal exchanges of knowledge".
The second main solution can be categorized as 'indepth analysis'. This term implies that both the preparation of a global sourcing process needs to be done thoroughly and that the requirements during the sourcing process have to be communicated clearly. "Before considering [the option to source globally], the enterprise must carry out an in-depth analysis of the advantages and risks it involves" (Gonzalez et al., 2006, p. 1244). Multi-criteria decision processes should be utilized in the supplier selection process to ensure that all risks are covered (Schönherr et al., 2008; Zhen, 2014). Kang et al. (2012, p. 1198) stress "the importance of clear outcome objectives regardless of the types of 
outsourcing". Overall, it is crucial to bear the total costs in mind (Bygballe et al., 2012; Platts \& Song, 2010) and to include costs for failed projects (Horn et al., 2013).

Training, as a means to close the gap resulting from cultural differences, is of vital importance for a profitable and successful business (Roth et al., 2008; Wilkinson et al., 2005; Mosco, 2006; Chen et al., 2010). "Training that includes technical assistance and the transfer of best practices is urgently necessary to bridge the gap between local norms and international expectations (Roth et al., 2008, p. 34).

Several researchers suggest a differentiation strategy when sourcing from China in order to minimize the risks. A tailored sourcing approach is most efficient, since "the constant base allocation allows China to focus on cost efficiency, whereas Mexico's quick response is utilized only dynamically to guarantee high service" (Allon and van Mieghem, 2010, p. 123). It follows that the Chinese market is attractive for sourcing standard and mass-produced products, while highly customized and low-volume products are more efficiently sourced locally (Fredriksson et al., 2010; Murray et al., 2005; Tung \& Wan, 2013).

As addressed above, communication represents a barrier to successful sourcing processes from China. Thus it is crucial to implement extensive and regular communication processes (Zhang et al., 2013), including the exchange of ideas, recommendations and requirements (Schönherr et al., 2008; Salmi, 2006). In order to track quality and collaboration, thorough control mechanisms have to be in place (Sethi et al., 2011), and illicit behavior can be reduced by the introduction of formal structures (Millington et al., 2005). Another means to shorten the distance between customers and Chinese suppliers, which also helps to enhance the mutual understanding, is to employ an intermediary (Nassimbeni \& Sartor, 2006; Fredriksson \& Jonsson, 2009; Wang et al., 2011).

Further solutions that were mentioned once in the sample size include implementation of supplier certifications (Roth et al., 2008), the use of common technology in China and the home country (Merminod \& Rowe, 2012), customized contract manufacturing (Tung \& Wan, 2013), an in-house focus on core competencies (Kumar et al., 2010; Dierks et al., 2013), an increasing level of innovation in China (Li et al., 2008), and resolving corruption by implementing a common code of conduct (Wilkinson et al., 2005).

\section{DISCUSSION}

A summary of answers to the research questions is found in Table 5.

\subsection{Motivations for Sourcing from China}

According to Salmi et al. (2006, p. 205) "low costs were seen to be the main motivation for sourcing from China", which is in line with Kumar et al. (2009b), Marion et al. (2007), and Enderwick (2009), who all underline that lower and lower labor costs are motivations for sourcing from China.

Apart from the monetary motivation, Gonzalez et al. (2006), Towers and Song (2010), and Drayse (2008) emphasize motivators such as flexibility and capacity. Jia et al. support this, since all studied companies identified costs as a motivation. However, this driver was not identified as the single or main driver.

Lead-time reduction is generally thought of as reducing the time from suppliers to the local market. The aspect of lead-time is mentioned only mentioned in 3 out of the 49 articles (i.e. Jia et al., 2014; Wang et al., 2011; Zhang et al., 2013).

The size of the domestic Chinese market is an advantage for companies that require rare components (Kierzkowski, 2011; Marion et al. 2007). In addition, certain skills are often targeted in the Chinese market (Jia et al., 2014; Stringer et al., 2011).

Finally, capacity is an important aspect when sourcing from China. According to Drayse (2008, p. 260) Chinese suppliers ' $[\ldots]$ operate 'megaplants' that employ thousands of workers $[\ldots]$ ", which further enlarge their capacity. As a result, a satisfying price-quality ratio can be achieved in China, which is particularly attractive for sourcing textiles (Takala et al., 2007).

\subsection{Achieved Outcomes when Sourcing from China}

Wang et al. (2011, p. 425) found out that their sample "of Australian companies indicated that their overall production result as a result of sourcing from China was better than domestic sourcing", which is in line with Kang et al. (2012, p. 1199), who emphasize that "all the case firms show satisfactory results in financial performance and strategic performance".

However, a particular drawback of sourcing from China is that "companies tend to underestimate the add-on costs of sourcing from China" (Platts \& Song, 2010, p. 329), "projects were successful at an operational level, but lacked behind in terms of financial performance" (Horn et al., 2013, p. 32), and financial benefits "are often overstated relative to other risks" (Kumar et al., 2010, p. 1896).

Besides an over-estimated cost saving effect, Salmi (2006, p. 205) highlights that "none of the respondents raised the question of how significant the cost advantage actually was from sourcing in China". This is partially in conflict with the fact that researchers discuss the strategy of entering the Chinese market as one of strategic importance to the overall growth (Jia et al., 2014).

Besides the monetary effect, a gain in market specific knowledge and local habits can be generated (Salmi, 2006; Drayse, 2008), future dynamics of the Chinese or Asian market can be identified (Dierks et al., 2013), and the knowledge intensity and exchange with the suppliers can be improved (Bunyaratavej et al., 2008; Zhang et al., 2013), entailing that, gaining knowledge and expertise are important aspects.

On the other side of the argument, only one article focuses on the negative impacts of sourcing from China. Fredriksson and Jonsson (2009, p. 245) discuss poor performance and argue that "the characteristics of low-costcountry supply chains affect the operational supply chain performance and decrease the sought-after positive effects of outsourcing, such as cost savings". 
Table 5 Research questions and answers

\begin{tabular}{l|l} 
Research question & Answer
\end{tabular}

\begin{tabular}{l|l} 
(1) What are the motivations for sourcing from & While the study revealed various motivations for sourcing from
\end{tabular} China?

China, the most important ones that were identified are cost savings, flexibility, availability, expansion and shorter lead-times. These are closely linked to each other and vary only slightly according to the specific sourcing strategy employed.

(2) What outcomes are achieved while sourcing from China?

Regarding the achieved outcomes, a mixed outcome was frequently identified, which implies that both positive and negative outcomes were experienced. However, the anticipated cost savings, which were mentioned as the most frequent motivation for sourcing from China, were not entirely met. Overall, costs were higher than expected and in addition, unforeseen costs occurred. On the other hand, outcomes such as a gain in expertise, profitability, entering the Chinese or Asian market and gaining competitive advantage were discussed, which all demonstrate rather positive outcomes.

(3) What problems are encountered while sourcing from China?

Various difficulties were identified while sourcing from China, which are as well closely connected to each other. Differences in culture, quality and communication are the most significant ones. Cultural differences and problems in communicating in English lead to problems in the relationships with Chinese suppliers, which are essential for the success of any business. Accompanying, quality issues arise due to diverse interpretations and perceptions of what good and required quality is and also, reliability was experienced to have lower priorities in China. Moreover, cost levels were higher than anticipated due to both unforeseen costs and increasing labor costs in China. Further, laws and regulations in China make the business more difficult and bear the risk of a loss of intellectual property.

(4) How are these problems dealt with?

In line with the discussed problems experienced when sourcing from China, potential problem solving approaches were identified. The establishment of long-term relationships with the Chinese business partners is seen to be crucial for successful sourcing processes. These long-term relationships encompass extensive communication processes, which also need to be carried out as face-to-face meetings on a regular basis. Prior to commencing sourcing processes, in-depth analyses were emphasized to be a means to ensure that the expected outcomes can be achieved. Such analyses imply thorough assessments of both the benefits and risks associated with sourcing from China. Within the starting process of sourcing activities from China, intermediaries are helpful to bridge the gap between the home countries and the Chinese culture and their way of doing business. Furthermore, it is useful to establish manifold control mechanisms in China as a means to ensure mutual understanding and desired quality levels.

\subsection{Problems Encountered when Sourcing from China}

A variety of problems are reported when sourcing from China. A major issue is a lack of mutual understanding. Wilkinson et al. (2005, p. 1895) state, "cross-cultural problems are problematic due to the Chinese concern with 'face', which can limit and distort the full and accurate exchange of information". Companies sourcing from China experience the Chinese suppliers' unwillingness to acknowledge problems, which leads to cultural clashes (Roth et al., 2008; Salmi, 2006). Besides problems in the general communication, different perceptions exist of what good quality is (Fredriksson and Jonsson, 2009; Horn et al., 2013), and product quality in China is lower than in other regions such as Europe (Horn et al., 2013; Schönherr et al., 2008). The risk of obsolescence (Roth et al., 2008) and poor working practices may occur (Wilkinson et al., 2005). Concluding, Roloff and Aßländer (2010) point out that lacking commitment breeds difficult buyer-supplier relationships. Thus, Enderwick (2009) notes that it is particularly difficult to set up relationships with Chinese suppliers and to find reliable and good partners that share values.

Apart from different interpretations regarding the content of the buyer-supplier relationship, the language barrier is the main reason for miscommunication (Gonzalez 
et al., 2006; Lin \& Ma, 2012; Takala et al., 2007; Towers \& Song, 2010). Consequently, an inaccurate transmission of component specification is a frequent problem (Enderwick, 2009). However, the core of miscommunication is interpreted differently, as Jia et al. (2014, p. 295) discuss a "lack of communication skills or unwillingness to communicate".

Even though cost savings has been identified as main motivation for sourcing from China, the aspect of hidden costs arises (Wang et al., 2011; Gonzalez et al., 2006). Platts and Song (2010, p. 329) confirm the aspect of hidden costs stating: "companies need to add about 50 per cent of the quoted price to get an indication of the total costs of outsourcing from China". Reasons for hidden costs could be the lacks in clarity regarding the Chinese laws and regulations (Vanhonacker \& Yigang, 1997), and a high level of complexity with customs and its procedures (Takala et al., 2007; Towers \& Song, 2010). In addition, Sethi et al. (2011, p. 485) point out that "global companies were under fire for operating factories with working conditions that violated basic human rights and labor laws in terms of wages and working conditions". As a result of both miscommunication and geographical distance, long lead-times occur, which result in a decreased flexibility (Allon \& van Mieghem, 2010; Woxenius, 2006; Schönherr et al., 2008). Therefore, outsourcing processes bear the risk of losing control of the company's business as Kang et al. (2012, p. 1200) conclude that the "loss of control is an important reason for outsourcing failures".

\subsection{Solutions to Problems when Sourcing from China}

In order to avoid the misinterpretations and miscommunication, regular and intensive communication is suggested to ensure specifications (Salmi, 2006; Kumar et al., 2010; Schönherr et al., 2008). Zhang et al. (2013, p. 1094) summarize that "only through intensive and regular communications can an outsourcer acquire knowledge about partners' ability to execute tasks, the complementarities of the resources and capabilities and the compatibility of organizational culture".

Aspects such as the creation of trust (Bygballe et al., 2012; Chen \& McQueen, 2010), the exchange of information (Gonzalez et al., 2006; Li et al., 2008; Merminod \& Rowe, 2012), and the establishment of personal relationships (Chen et al., 2010; Lo \& Chung, 2007) are means to ensure an efficient long-term relationship with Chinese suppliers. Learning about culture is one building block in the efforts to build such a relationship, since it contributes to bridging the differences (Roth et al., 2008; Wilkinson et al., 2005; Mosco, 2006).

As a means to reduce quality issues, control mechanisms are suggested (Franca et al., 2010). These include audits (Sethi et al., 2011), the introduction of international production standards (Millington et al., 2005; Olson \& Wu, 2011), and supplier certifications are discussed as means to ensure certain quality standards (Roth et al., 2008).

Along with the specific solutions, academics highlight the importance of in-depth analysis (Fredriksson et al. 2010; Woxenius 2006), which implies that "before considering this option [sourcing from China] the enterprise must carry out an in-depth analysis of the advantages and risks it involves" (Gonzalez et al. 2006, p. 1244). In addition, the companies aim at keeping core competencies and highly specialized components in-house, which is supported by Dierks et al. (2013). However, in literature differentiation is defined as sourcing standard and mass-produced components and products from China, and highly innovative products rather locally (Allon \& van Mieghem, 2010; Fredriksson et al., 2010; Murray et al., 2005).

As can be seen, there is not always a solution to a specific problem. Whereas it is important to find solutions to all problems, this should not be expected when summarizing research in this manner. It is to be expected that empirical research uncovers problems to which there is currently no solution. Here solutions to problems with, for example, mutual understanding, language barriers, cultural differences and quality could be identified. However, areas such as working practices, risk of obsolence, and decreased flexibility were not discussed in the included papers. This is not to say that there is no knowledge. Other researchers have discussed similar issues with how to take responsibility for working practices (e.g. Eriksson et al, 2013; Egels-Zandén, 2015), and reduce the risk of obsolence and reduced flexibility (e.g. Hilletofth, 2009; Hilletofth, 2010; Yi et al., 2011).

\section{CONCLUDING REMARKS}

The analysis has shown that it is crucial to recognize the importance of problems that can occur during global sourcing processes. As to achieve the desired outcomes, it is essential that companies address the problems by developing appropriate solutions. Motivations, outcomes, problems and solutions contain essential aspects that have to be considered and worked upon during a global sourcing process.

\subsection{Contributions and Implications}

The aim of the paper was to fill a gap in literature by exploring and analyzing the motivations for sourcing from China, achieved outcomes, experienced problems as well as solutions. Thereby, this paper aimed at filling a gap in the theory of global sourcing. The results demonstrate that companies experience a changing environment in China and thus, the literature has to be updated frequently, which is important for academics.

The main implications for practitioners are to bear in mind the four aspects of motivations, outcomes, problems and solutions when sourcing from China. Even though companies usually have a clear motivation and ambition to commence sourcing from China, they lack in efficient and considerate coordination and execution of these processes. It is crucial to carry out in-depth analysis bearing all risks and costs in mind to reap the desired benefits. It is of vital importance to consider the cultural differences that have an enormous effect on the business relationships with Chinese suppliers. In order to benefit from attractive business opportunities, both time and effort should not be underestimated. Hence, it is essential to think ahead by taking all upcoming opportunities and risks into account, such as rising labor costs, in order to create successful longterm business relationships.

The purpose of the study was to explore and analyze sourcing from China. Doing so, this paper has contributed to 
academics and practitioners by emphasizing the importance of frequently updated global sourcing theory in terms of sourcing from China. Furthermore, motivations, outcomes, problems and solutions have been identified as important aspects in order to successfully source from China.

\subsection{Limitations and Further Research}

The focus of the systematic literature review is on a very specified topic and due to the fact that the sample size did not contain an equal number of articles for every year, trends over time cannot be discovered. Hence, in this specific paper the systematic literature review does not represent a means to allow statistically correct rankings and conclusions. The problems and solutions identified also reveal that this literature review was not able to capture all knowledge that is available in the field. In and of itself this is not a failure of the literature review, rather a result of the necessity of delimitations needed to be able to operationalize the research. It also presents a venue for further research focusing specifically on problems and solutions.

To add more insights to the theory of global sourcing, and motivations, outcomes, experienced problems and solutions, case studies would be beneficial in order to verify the findings or to emphasize differences, for instance between Northern and Southern European countries. In addition, different countries' perspectives would allow analyzing patterns and relationships at a greater detail.

\section{REFERENCES}

Adolphos, M. (2015). How to carry out a literature review for a dissertation or research paper. Retrieved 2015-02-24, from http://www.emeraldgrouppublishing.com/research /guides/methods/literature2.htm?part=1

Allon, G., \& van Mieghem, J. A. (2010). Global dual sourcing: tailored base-surge allocation to near- and offshore production. Management Science, 56(1), pp. 110-124.

Aromataris, E., \& Pearson, A. (2014). The Systematic Review: An Overview Synthesizing research evidence to inform nursing practice. American Journal of Nursing, 114(3), pp. 53-58.

Brewerton, P., \& Millward, L. (2001). Organizational research methods. London: Sage.

Bunyaratavej, K., Hahn, E. D., \& Doh, J. D. (2008). Multinational investment and host country development: Location efficiencies for services offshoring. Journal of World Business, 43(2), pp. 227-242.

Bygballe, L. E., Bo, E., \& Gronland, S. E. (2012). Managing international supply: The balance between total costs and customer service. Industrial Marketing Management, 41(3), pp. 394-401.

Canham., S \& Hamilton, R.T. (2013). SME internationalization: offshoring, "backshoring", or staying home in New Zealand. Strategic Outsourcing: An International Journal, 6(3), pp. 277-291.

Carter, C. R., \& Easton, P. L. (2011). Sustainable supply chain management: evolution and future directions. International Journal of Physical Distribution \& Logistics Management, 41(1), pp. 46-62.

Chen, J., \& McQueen, R. J. (2010). Knowledge transfer processes for different experience levels of knowledge recipients at an offshore technical support centre. Information, Technology \& People, 23(1), pp. 54-79.

Chen, J., Sun, P. Y. T., \& McQueen, R. J. (2010). The impact of national cultures on structured knowledge transfer. Journal of Knowledge Management, 14(2), pp. 228-242.

Christopher, M., Mena, C., Khan, O., \& Yurt, O. (2011).
Approaches to managing global sourcing risk. Supply Chain Management: An International Journal, 16(2), pp. 67-81.

Dierks, A., Kuklinski, C., \& Moser, R. (2013). How Institutional Change Reconfigures Successful Value Chains: The Case of Western Pharma Corporations in China. Thunderbird International Business Review, 55(2), pp. 153-171.

Drayse, M. H. (2008). Globalization and Regional Change in the U.S. Furniture Industry. Growth and Change, 39(2), pp. 252282.

Dubois, A. \& Gadde, L.-E. (2002). Systematic Combining: An Abductive approach to Case Research. Journal of Business Research, 55(7), pp. 553-560.

Egels-Zandén, N. (2015). Responsibility boundaries in global value chains: supplier audit prioritizations and moral disengagement among Swedish firms. Journal of Business Ethics [accepted for publication, available as 'Online first'].

Eisenhardt, K. (1989). Building Theories from Case Study Research. Academy of Management Review, 14(4), pp. 532550.

Enderwick, P. (2009). Avoiding quality fade in Chinese global supply chains - Designing appropriate governance structures. Business Process Management Journal, 15(6), pp. 876-894.

Eriksson, D. (2015). Lessons on knowledge creation in supply chain management. European Business Review, 27(4), pp. 346-368.

Eriksson, D., Hilletofth, P., and Hilmola, O-P. (2013). Linking moral disengagement to supply chain practices. World Review of Intermodal Transportation Research, 4(2/3), pp. 207-225.

Feenstra, R. C., \& Hanson, G. H. (2005). Ownership and control in outsourcing to China: Estimating the property-rights theory of the firm. Quarterly Journal of Economics, 120(2), pp. 729761.

Franca, R. B., Jones, E. C., Richards, C. N., \& Carlson, J. P. (2010). Multi-objective stochastic supply chain modeling to evaluate trade-offs between profit and quality. International Journal of Production Economics, 127(2), pp. 292-299.

Fredriksson, A., \& Jonsson, P. (2009). Assessing consequences of low-cost sourcing in China. International Journal of Physical Distribution \& Logistics Management, 39(3), pp. 227-249.

Fredriksson, A., Jonsson, P., \& Medbo, P. (2010). Utilising the potential of combining local and global supply chains. International Journal of Logistics: Research and Applications, 13(4), pp. 313-326.

Giménez, C. \& Tachizawa, E.M. (2012). Extending sustainability to suppliers: a systematic literature review. Supply Chain Management: An International Journal, 17(5), pp. 531-543.

Gonzalez, R., Gasco, J., \& Llopis, J. (2006). Information systems offshore outsourcing: A descriptive analysis. Industrial Management \& Data Systems, 106(9), pp. 1233-1248.

Hilletofth, P. (2009). How to develop a differentiated supply chain strategy. Industrial Management \& Data Systems, 109(1), pp. 16-33.

Hilletofth, P. (2010). Demand-supply Chain Management, Doctoral thesis, Chalmers University of Technology, Gothenburg, Sweden.

Hilletofth, P., and Hilmola, O-P. (2010). Role of logistics outsourcing on supply chain strategy and management: Survey findings from Northern Europe. Strategic Outsourcing: An International Journal, 3(1), pp. 46-61

Holweg, M., Reichhart, A., \& Hong, E. (2011). On risk and cost in global sourcing. International Journal of Production Economics, 131(1), pp. 333-341.

Horn, P., Schiele, H., \& Werner, W. (2013). The "ugly twins": Failed low-wage-country sourcing projects and their expensive replacements. Journal of Purchasing \& Supply Management, 19(1), pp. 27-38.

Jia, F., Lamming, R., Sartor, M., Orzes, G., \& Nassimbeni, G. (2014). Global purchasing strategy and International Purchasing Offices: Evidence from case studies. International Journal of Production Economics, 154(2014), 
pp. $284-298$.

Kamann, D. J., \& van Nieulande, V. (2010). A Four-filter Method for Outsourcing to Low-cost Countries. Journal of Supply Chain Management, 46(2), pp. 64-79.

Kang, M., Wu, X., Hong, P., \& Park, Y. (2012). Aligning organizational control practices with competitive outsourcing performance. Journal of Business Research, 65(8), pp. 1195-1201.

Kierzkowski, H. (2011). A New Global Auto Industry. China \& World Economy, 19(1), pp. 63-82.

Kinkel, S., \& Maloca, S. (2009). Drivers and antecedents of manufacturing offshoring and backshoring - a German perspective. Journal of Purchasing \& Supply Management, 15(3), pp. 154-165.

Kumar, S., Medina, J., \& Nelson, M. T. (2009b). Is the offshore outsourcing landscape for US manufacturers migrating away from China? Supply Chain Management: An International Journal, 14(5), pp. 342-348.

Kumar, S., Zampogna, P., \& Nansen, J. (2010). A closed loop outsourcing decision model for developing effective manufacturing strategy. International Journal of Production Research, 48(7), pp. 1873-1900.

Lemoine, F. (2010). Past Successes and New Challenges: China's Foreign Trade at a Turning Point. China \& World Economy, 18(3), pp. 1-23.

Li, Y., Liu, Y., Li, M., \& Wu, H. (2008). Transformational offshore outsourcing: Empirical evidence from alliances in China. Journal of Operations Management, 26(2), pp. 257-274.

Lin, S., \& Ma, A. C. (2012). Outsourcing and productivity: Evidence from Korean data. Journal of Asian Economics, 23(1), pp. 39-49.

Lo, C. Y., \& Chung, W. C. (2007). A study of outsourcing relationship in strategic partnership for production in China. International Journal of Logistics Systems and Management, 3(3), pp. 288-304.

Marion, T. J., Thevenot, H. J., \& Simpson, T. W. (2007). A costbased methodology for evaluating product platform commonality sourcing decisions with two examples. International Journal of Production Research, 45(22), pp. 5285-5308.

Mayring, P. (2003). Qualitative Inhaltanalyse - Grundlagen und Techniken ( $8^{\text {th }}$ ed.). Weinheim: Beltz Verlag.

Merminod, V., \& Rowe, F. (2012). How does PLM technology support knowledge transfer and translation in new product development? Transparency and boundary spanners in an international context. Information \& Organization, 22(4), pp. 295-322.

Millington, A., Eberhardt, M., \& Wilkinson, B. (2005). Gift giving, Guanxi and Illicit Payments in Buyer-Supplier Relations in China: Analysing the Experience of UK Companies. Journal of Business Ethics, 57(3), pp. 255-268.

Mosco, V. (2006). Knowledge and Media Workers in the Global Economy: Antimonies of Outsourcing. Social Identities, 12(6), pp. 771-790.

Murray, J. Y., Kotabe, M., \& Zhou, J. N. (2005). Strategic alliancebased sourcing and market performance: evidence from foreign firms operating in China. Journal of International Business Studies, 36(2), pp. 187-208.

Nassimbeni, G., \& Sartor, M. (2006). International purchasing offices in China. Production Planning \& Control, 17(5), pp. 494-507.

Ni, D., Li, K. W., \& Tang, X. (2009). Production costs, scope economics, and multi-client outsourcing under quantity competition. International Journal of Production Economics, 121(1), pp. 130-140.

Olson, D. L., \& Wu, D. (2011). Risk management models for supply chains: a scenario analysis of outsourcing to China. Supply Chain Management: An International Journal, 16(6), pp. 401-408.
Platts, K. W., \& Song, N. (2010). Overseas sourcing decisions - the total cost of sourcing from China. Supply Chain Management: An International Journal, 15(4), pp. 320-331.

Roloff, J., \& Aßländer, M. S. (2010). Corporate Autonomy and Buyer-Supplier Relationships: The Case of Unsafe Mattel Toys. Journal of Business Ethics, 97(4), pp. 517-534.

Roth, A. V., Tsay, A. A., Pullman, M. E., \& Gray, J. V. (2008). Unravelling the food supply chain: strategic insights from China and the 2007 recalls. Journal of Supply Chain Management, 44(1), pp. 22-39.

Salmi, A. (2006). Organising international supplier relations: An exploratory study of Western purchasing in China. Journal of Purchasing \& Supply Management, 12(4), pp. 197-208.

Saunders, M., Lewis, P., \& Thornhill, A. (2012). Research methods for business students ( $6^{\text {th }}$ ed.). London: Pearson.

Schönherr, T., Tummala, R., \& Harrison, T. P. (2008). Assessing supply chain risks with the analytic hierarchy process: Providing decision support for the offshoring decision by a US manufacturing company. Journal of Purchasing \& Supply Management, 14(2), pp. 100-111.

Sethi, S. P., Veral, E. A., Shapiro, H. J., \& Emelianova, O. (2011). Mattel, Inc.: Global Manufacturing Principles (GMP) - A Life-Cycle Analysis of a Company-Based Code of Conduct in the Toy Industry. Journal of Business Ethics, 99(4), pp. 483-517.

Stringer, C., Simmons, G., \& Rees, E. (2011). Shifting post production patterns: Exploring changes in New Zealand's seafood processing industry. New Zealand Geographer, 67(3), pp. 161-173.

Susomrith, P., \& Brown, A. (2013). Motivations for HR outsourcing in Australia. The International Journal of Human Resource Management, 24(4), pp. 704-720.

Svensson, G. (2013). Processes of substantiations and contributions through theory building towards theory in business research. Europan Business Review, 25(5), pp. 466-480.

Takala, J., Hirvelä, J., Liu, Y., \& Malindzak, D. (2007). Global manufacturing strategies require "dynamic engineers"? Case study in Finnish industries. Industrial Management \& Data Systems, 107(3), pp. 326-344.

Towers, N., \& Song, Y. (2010). Assessing the future challenges in strategic sourcing commodity from China: a case-study analysis. Asia Pacific Business Review, 16(4), pp. 527-544.

Tung, A.-C., \& Wan, H. Jr. (2013). Chinese Electronics Export; Taiwanese Contract Manufacturing - The Win-Win Outcome along the Evolving Global Value Chain. The World Economy, 36(7), pp. 827-842.

Wang, J., Singh, P. J., Samson, D., \& Power, D. (2011). Sourcing from China: experiences of Australian firms. Supply Chain Management: An International Journal, 16(6), pp. 419-427.

Vanhonacker, W., \& Yigang, P. (1997). The Impact of National Culture, Business Scope, and Geographic Location on Joint Venture Operations in China. Journal of International Marketing, 5(3), pp. 11-30.

Wilkinson, B., Eberhardt, M., McLaren, J., \& Millington, A. (2005). Human resource barriers to partnership sourcing in China. International Journal of Human Resource Management, 16(10), pp. 1886-1900.

Wiesmann, B., Snoei, J.R., Hilletofth, P., and Eriksson, D. (2017) Drivers and barriers to reshoring: A literature review on offshoring in reverse. European Business Review, 29(1), pp. $15-42$

World Trade Organization (2015). China and the WTO. Retrieved 2015-04-10 from https://www.wto.org/english/thewto_e/countries_e/china_e. $\mathrm{htm}$

Woxenius, J. (2006). Temporal Elements in the Spatial Extension of Production Networks. Growth and Change, 37(4), pp. 526- 
549.

Yi, C.Y., Ngai, E.W.T., and Moon K-L. (2011). Supply chain flexibility in an uncertain environment: exploratory findings from five case studies. Supply Chain Management: An International Journal, 16(4), pp. 271-283.

Zeng, A. Z., \& Rossetti, C. (2003). Developing a framework for evaluating the logistics costs in global sourcing processes - an implementation and insights. International Journal of Physical Distribution \& Logistics Management, 33(9), pp. 785-803.

Zhang, M., Pawar, K. S., Shah, J., \& Mehta, P. (2013). Evaluating outsourcing partners' capability: a case study from the pharmaceutical supply chain. Journal of Manufacturing Technology Management, 24(8), pp. 1080-1101.

Zhen, L. (2014). A three-stage optimization model for production and outsourcing under China's export-oriented tax policies. Transportation Research, 69, pp. 1-20.

Åkesson, J., Jonsson, P., \& Edanius-Hällås, P. (2007). An assessment of sourcing strategies in the Swedish apparel industry. International Journal of Physical Distribution \& Logistics Management, 37(9), pp. 740-762.

Kristina Kerkhoff (MSc) is a former student of Jönköping University in Sweden and holds a Master degree in Business Administration with a major in International Logistics and Supply Chain Management. She currently works as a consultant for one of the leading European consultancies in the area of procurement and supply chain management.

Kevin Kaul (MSc) is a former student of Jönköping University in Sweden and holds a Master degree in Business Administration with a major in International Logistics and Supply Chain Management. He currently works as a logistics management trainee in the area of supply chain management for the world's largest cosmetic company.

Per Hilletofth (PhD) is a Professor of Operations and Supply Chain Management at Jönköping University in Sweden. His research focuses on demand-supply integration, operations strategy, supply chain relocation, product development, and decision support. He has editorial assignments in several international journals.

David Eriksson (PhD) is a researcher and lecturer at Jönköping University in Sweden. He holds a PhD in Textile Management, and has a research background in logistics and transportation. Furthermore, he is an engaged scholar in the international research community. He is an author of international journal articles and international conference contributions. His research agenda consists of various research subjects including corporate social responsibility, methodology, new product development, supply chain management, sustainability, and waste management. He is currently in the Editorial Board for World Review of Intermodal Transportation Research, and the Editorial Review Board for Industrial Management \& Data Systems. 